International Journal of Automotive and Mechanical Engineering (IJAME) ISSN: 2229-8649 (Print); ISSN: 2180-1606 (Online);

Volume 13, Issue 2 pp. 3309 - 3328, September 2016

CUniversiti Malaysia Pahang Publishing

DOI: https://doi.org/10.15282/ijame.13.2.2016.3.0275

\title{
Single-zone zero-dimensional model study for diesel-fuelled homogeneous charge compression ignition (HCCI) engines using Cantera
}

\author{
A. Aziz Hairuddin ${ }^{1 *}$, Talal Yusaf ${ }^{2}$ and Andrew P. Wandel ${ }^{3}$ \\ ${ }^{1}$ Department of Mechanical and Manufacturing Engineering \\ Faculty of Engineering, Universiti Putra Malaysia, \\ 43400 UPM Serdang, Selangor, Malaysia. \\ *Email: ahziz@upm.edu.my \\ ${ }^{2}$ National Centre for Engineering in Agriculture, \\ School of Mechanical and Electrical Engineering \\ University of Southern Queensland, Toowooomba, 4350 QLD, Australia \\ ${ }^{3}$ Computational Engineering and Science Research Centre \\ School of Mechanical and Electrical Engineering \\ University of Southern Queensland, Toowooomba, 4350 QLD, Australia.
}

\begin{abstract}
Homogeneous charge compression ignition (HCCI) engine technology is relatively new and the combustion behavior in an HCCI engine is difficult to predict. The combustion is fully controlled by the chemical kinetics and the chemical reaction of the mixture is influenced by changing input parameters. A zero-dimensional single-zone model was used to investigate the combustion behavior of a diesel engine operating in HCCI mode. An open source chemical kinetics package from Cantera was used in this study. The combustion behaviour can be observed, where $\mathrm{H}_{2} \mathrm{O}_{2}$ was fully decomposed during the main combustion event. The time for $\mathrm{H}_{2} \mathrm{O}_{2}$ to completely decompose into $\mathrm{OH}$ radicals was very short, which was about $5^{\circ} \mathrm{CA}$. The combustion phasing was predicted in accordance with the experiment. The auto-ignition can be controlled by controlling the intake temperature or AFR. The start of combustion was advanced by increasing the intake temperature from 20 to $70^{\circ} \mathrm{C}$ and reducing the AFR from 58 to 29 . However, reducing AFR will increase the in-cylinder peak pressure. In general, a zero-dimensional model is a useful and faster tool to predict the combustion phasing. When coupled with chemical kinetics, it provides more accurate results.
\end{abstract}

Keywords: diesel, HCCI, Cantera, n-heptane, single-zone, zero-dimensional.

\section{INTRODUCTION}

Homogeneous charge compression ignition (HCCI) engines have received increasing attention recently because of their advantages in reducing emissions levels, such as $\mathrm{NO}_{\mathrm{x}}$ [1-6]. An attempt by regulatory bodies, such as those in Europe, the United States (US) and Japan, to reduce emissions levels from conventional engines [7-9] has made the HCCI engines a viable alternative for low emissions engines. Electric vehicles offer virtually zero emissions; however, battery technology used in electric vehicles has not matured sufficiently. Primary disadvantages include a longer recharge time and limited mileage per charge. If global emissions (from vehicles, industries and electric power generators, among others) are to be the major concerns, electric vehicles still have emissions generated from the power plant generator. The power plant generator usually uses 
conventional engines to get electric energy, except when using renewable energy sources (such as hydropower, solar or wind turbine). Thus, this is where the HCCI engine comes into place, where it can be used in any engine configuration: stationary, vehicles or ship engines.

An HCCI engine can be considered a new technology, even though the first research associated with it (with gasoline fuel) dated back to 1979, by Onishi et al. [10]. The HCCI technique is the process by which a homogeneous mixture of air and fuel is compressed until auto-ignition occurs near the end of the compression stroke, followed by a combustion process that is significantly faster than either compression ignition (CI) or spark ignition (SI) combustion [11-14]. The air/fuel mixture quality in HCCI engines is generally lean, auto-ignites in multiple locations and is then burned volumetrically without discernible flame propagation [15-18]. Combustion occurs when the homogeneous mixture has reached its chemical activation energy and is fully controlled by chemical kinetics [19], rather than by a spark or injection timing. Because the chemical kinetics fully control the mixture, the engine is difficult to start in cold conditions. Apart from that, the disadvantages of HCCI engines are as follows: 1) difficult to control the auto-ignition; 2) they have a high heat release rate at high loads; 3) they have high levels of unburned hydrocarbon (UHC) and carbon monoxide and 4) they knock under certain operating conditions [20-23]. However, an HCCI engine offers some advantages, wherein the following occur: 1) there is a high engine efficiency relative to spark ignition (SI) engines [24, 25]; 2) there is the ability to operate on a wide range of fuels [25-27]; and 3) there is the ability to be used in any engine configuration [28-30].

A diesel-fuelled engine was investigated in this study because the engine is stronger due to it having higher torque than SI engines, as well as the fact that it is mostly used in agricultural areas [12, 31-34]. The engine could be used in a stationary form or for vehicles. The use of an HCCI configuration for a diesel-fuelled engine could be the future of diesel engines due to the advantages in producing ultra-low nitrogen oxides $\left(\mathrm{NO}_{\mathrm{x}}\right)$, soot emissions and higher fuel conversion efficiency [35-37]. Biodiesel could also be used in HCCI engines, as it currently receives increasing attention from researchers worldwide [38-44] as a renewable energy or for vehicle engines. Various researchers have investigated the HCCI engine both experimentally [45-48] and numerically [45, 49-51]. Many numerical studies used a computational fluid dynamics (CFD) approach to obtain more accurate results of combustion temperature and products [52-59]. A CFD approach uses more computational power and time compared to a single-zone thermodynamics simulation. Thermodynamics models are unable to match the CFD results in terms of accuracy; however, they are still able to predict a combustion behavior comparable to experiments [60]. Better agreement in combustion phasing is achieved when the thermodynamics model is coupled with detailed chemical kinetics and turbulent mixing effects [15]. The purpose of this paper was to study the combustion behavior of dieselfuelled HCCI engines using the thermodynamics single-zone zero-dimensional model, coupled with Cantera [61] as a chemical kinetics library. Cantera is an open-source chemical kinetics library that has not been widely used in engine simulations. Most of the numerical studies in engines today used Chemkin as a chemical kinetics library [62-64], which is no longer freely available. The availability of an open-source library is, therefore, beneficial for new researchers. This study discusses the numerical model used in Section 2, followed by its validation in Section 3 along with the chemical reactions mechanism and methods of controlling the auto-ignition. The paper closes with the conclusion in Section 4.

\section{METHODS AND MATERIALS}


A zero-dimensional model uses time as the independent variable to model the combustion in the chamber. Time can be represented by $\theta$, which is the CA, because $\theta$ monotonically increases with time. In the next sub-sections, the equations used to model the zerodimensional environment for a single-cylinder engine are discussed. The zerodimensional model used in this study was initially developed by Assanis and Heywood [65]. However, some changes had been made: the current model used a different heat release rate model, a different valve motion model and utilised a detailed chemical reaction mechanism. The simulation began from the inlet valve open (IVO) and until the exhaust valve open (EVO) and the thermodynamics properties were assumed to be uniform throughout the combustion chamber. Then, all of the equations pertaining to the simulation were coded using the Matlab software, combined with an open-source chemical kinetics package.

\section{Engine Geometry}

The instantaneous volume at any crank angle position can be obtained from

$$
V_{i}=V_{c}\left[1+\frac{R_{c}-1}{2}\left(R+1-\cos \theta-\sqrt{R^{2}-\sin ^{2} \theta}\right)\right]
$$

where, $V_{c}$ is the clearance volume, $R_{c}$ is the compression ratio, and $R$ is the connecting rod length. Differentiating equation (1) with respect to the crank angle, the rate of the change of volume is represented by

$$
\frac{d V}{d \theta}=V_{c}\left[\frac{R_{c}-1}{2}(\sin \theta)\left(\frac{1+\cos \theta}{\sqrt{R^{2}-\sin ^{2} \theta}}\right)\right]
$$

The change in volume is an important parameter, as these equations will be used to determine the piston work.

\section{Conservation of Mass}

The model of the thermodynamics system is an open system; thus, the mass flows in and out of the system, governing the total mass of the chamber

$$
\frac{d m}{d t}=\sum_{j} \dot{m}_{j}
$$

where, $\dot{m}$ is the mass flow rate, $m$ is the mass and the $j$ is the number of flows in or out of the system.

\section{Conservation of Energy}

The energy equation was derived from the first law of thermodynamics for an open system

$$
\frac{d m u}{d t}=\frac{d Q}{d t}-P \frac{d V}{d t}+\sum_{j} \dot{m}_{j} h_{j}
$$

where, $u$ is the specific internal energy, $Q$ is the net heat transfer, $P$ is the in-cylinder pressure, $V$ is the instantaneous cylinder volume and $h$ is the specific enthalpy. After 
manipulating equation (4) (the derivation is shown in the appendices), the final equation for temperature changes in a zero-dimensional single-zone model is given [65] by

$$
\begin{aligned}
\frac{d T}{d t}= & \frac{1}{\bar{C}_{p}-\frac{P v}{T}}\left[\left(\frac{P v \sum_{i} R_{i}}{R_{u}}-\sum_{i} h_{i}\right) \frac{d Y_{i}}{d t}-\frac{\dot{m}}{m}(h-P v)\right. \\
& \left.+\frac{1}{m}\left(\frac{d Q_{h}}{d t}-P \frac{d V}{d t}+\sum_{j} \dot{m}_{j} h_{j}\right)\right]
\end{aligned}
$$

In equation (5), $\bar{C}_{p}$ is the specific heat at constant pressure, $T$ is the instantaneous incylinder temperature, $v$ is the specific volume, $R_{u}$ is the universal heat constant, $Y_{i}$ is the mass fraction of species $i, \dot{m}_{i n}$ is the mass flow rate into the cylinder and $Q_{h}$ is the heat loss to the cylinder wall. The derivation of equation (5) was discussed extensively by Assanis and Heywood [65]. Once the instantaneous in-cylinder temperature was obtained, the in-cylinder pressure will then be determined using the ideal gas equation, as

$$
P=\frac{\rho R_{u} T}{\overline{W_{m w}}} \quad \text { with } \quad \overline{W_{m w}}=\frac{1}{\sum_{1}^{n} Y_{i} / W_{i}}
$$

where, $\overline{W_{m w}}$ is the mean molecular weight of the mixture, $\rho$ is the density, $W_{i}$ is the molecular weight of the $i$ th species and $n$ is the total number of species.

The volume in equation (5) as a function of crank angle (CA), $\theta$, is given by

$$
\mathcal{V}=\mathcal{V}_{c}\left[1+\frac{R_{c}-1}{2}\left(R+1-\cos \theta-\sqrt{R^{2}-\sin ^{2} \theta}\right)\right]
$$

where $\mathcal{V}_{c}$ is the clearance volume, $R$ is the ratio of connecting rod length to crank radius and $R_{C}$ is the compression ratio.

To obtain the mass flow rate in and out of the chamber, the valve motion had to be modelled. Thus, to model the valve lift across the entire CA, a model from Assanis and Polishak [66] was employed. The valve lift profile, $y$, was determined by using the desired maximum valve lift $L_{v}$ and half-event angle $c$, then the profile as a function of CA is

$$
y=L_{v}+C_{2} \theta^{2}+C_{w} \theta^{w}+C_{q} \theta^{q}+C_{r} \theta^{r}+C_{s} \theta^{s}
$$

where $w, q, r$ and $s$ are constants to match the desired valve lift curve, which are selected as $w=6, q=8, r=10$ and $s=12$. The coefficients are

$$
\begin{aligned}
C_{2} & =\frac{-w q r s L_{v}}{\left[(w-2)(q-2)(r-2)(s-2) c^{2}\right]} \\
C_{w} & =\frac{2 q r s L_{v}}{\left[(w-2)(q-w)(r-w)(s-w) c^{w}\right]} \\
C_{q} & =\frac{-2 w r s L_{v}}{\left[(q-2)(q-w)(r-q)(s-q) c^{q}\right]}
\end{aligned}
$$




$$
\begin{aligned}
C_{r} & =\frac{2 w q s L_{v}}{\left[(r-2)(r-w)(r-q)(s-r) c^{r}\right]} \\
C_{s} & =\frac{-2 w q r L_{v}}{\left[(s-2)(s-w)(s-q)(s-r) c^{s}\right]}
\end{aligned}
$$

By using equation (8), a typical valve lift profile with tappet mechanism (mechanical lifters) is illustrated in Figure 1. Once the valve lift is known, the effective valve open area can be obtained. In this case, the effective valve open area was taken to be its curtain area, which is given by

$$
A_{c}=\pi D_{v} L_{v}
$$

In general, larger valve sizes (or more valves per cylinder) give higher maximum air flows in and out of the chamber. The mass flow rate to the combustion chamber can then be obtained by using the equation of compressible flow through a flow restriction [67]. The equation includes real gas flow effects with discharge coefficient $C_{d}$ obtained from experiments [68]. In principle, the mass flows in or out of the combustion chamber, when there is a pressure difference between the chamber and ports. The equation is separated into two cases: choked and subsonic flows. For choked flow,

$$
\begin{array}{r}
\left(p_{T} / p_{0} \leq\left[\frac{2}{\gamma+1}\right]^{\gamma / \gamma-1}\right) \\
\dot{m}_{\text {in }}=\frac{C_{d} A_{c} p_{0}}{\sqrt{R T_{0}}} \sqrt{\gamma}\left[\frac{2}{\gamma+1}\right]^{\gamma+1 / 2(\gamma-1)}
\end{array}
$$

while for subsonic flow,

$$
\begin{gathered}
\left(p_{T} / p_{0}>\left[\frac{2}{\gamma+1}\right]^{\gamma / \gamma-1}\right) \\
\dot{m}_{\text {in }}=\frac{C_{d} A_{c} p_{0}}{\sqrt{R T_{0}}}\left(\frac{p_{T}}{p_{0}}\right)^{1 / \gamma}\left\{\frac{2 \gamma}{\gamma-1}\left[1-\left(\frac{p_{T}}{p_{0}}\right)^{\gamma-1 / \gamma}\right]\right\}^{1 / 2}
\end{gathered}
$$

where $p_{T}, p_{0}, T_{0}$ and $\gamma$ are the downstream static pressure, upstream stagnation pressure, upstream stagnation temperature and ratio of specific heats, respectively. Equations (15) and (16) are functions of gas properties, valve geometry and thermodynamic states upstream and downstream of the valves. For flow into the combustion chamber, $p_{0}$ is the intake port pressure and $p_{T}$ is the cylinder pressure. On the other hand, $p_{0}$ is the cylinder pressure and $p_{T}$ is the exhaust port pressure for the flow out of the combustion chamber. The value $C_{d}$ was obtained experimentally from Stiesch [68]. Once the mass flow rate was determined, it will be used in the energy equation and also to obtain the total mass in the combustion chamber. 


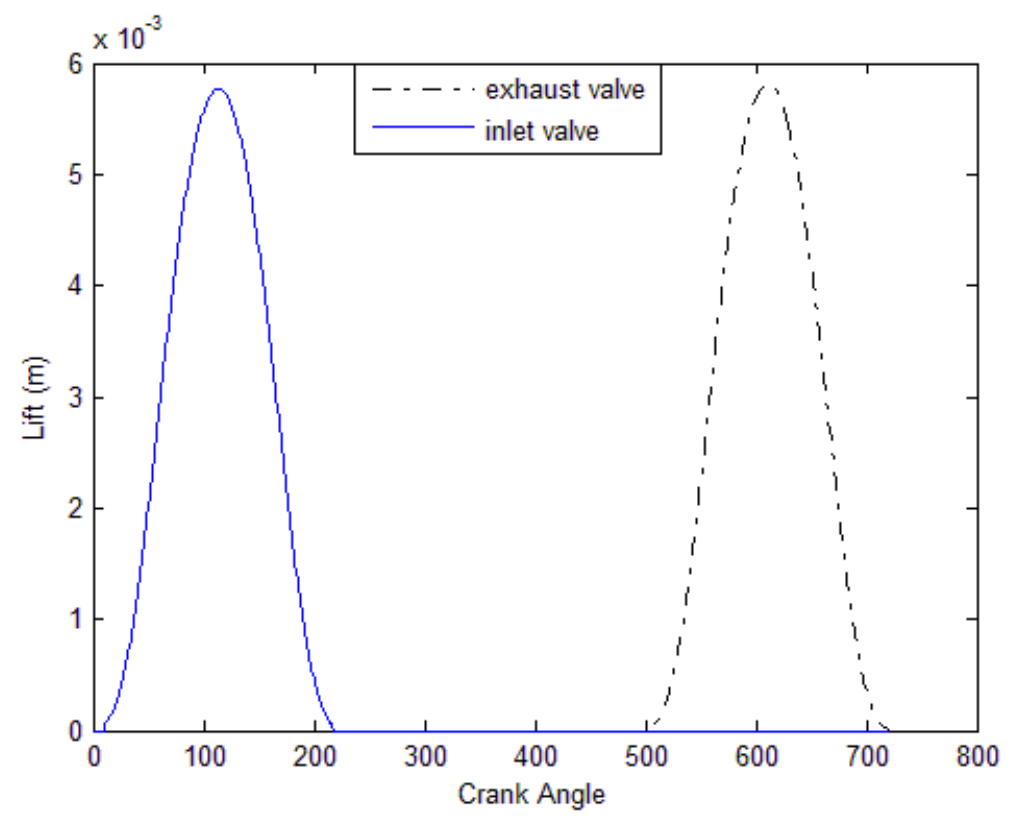

Figure 1. Valve lift profile for typical poppet valves with mechanical lifters.

\section{Conservation of Species}

The chemical reactions are the source term in the energy equation, wherein the temperature changes based on the energy being transferred from one form to another due to chemical reactions. Modeling the combustion with a chemical reaction mechanism is critical because chemical kinetics fully control the HCCI engines. In this study, an nheptane reduced mechanism [69] was used as a surrogate fuel to simulate diesel combustion. This was chosen because n-heptane's chemical properties are similar to that of conventional diesel in terms of the cetane number. The mechanism consists of 160 species and 770 elementary reactions. Thus, the change of mass fraction of each species due to chemical reactions is given by

$$
\frac{d Y_{i}}{d t}=\frac{\dot{\omega}_{i} W_{m w}}{\rho}, i=1, \ldots, n
$$

where, $\dot{\omega}_{i}$ is the molar production rate. The Cantera package was used to solve the chemical reaction mechanism. A readily available n-heptane mechanism file in the Chemkin format was then converted to Cantera format so that it could be used with the Cantera package. There was no change in the chemical reaction mechanisms; thus, no validation was required as of the chemical kinetics itself.

\section{Heat Transfer}

Heat is transferred between the cylinder walls and cylinder gases via convection and radiation. The radiation effect is neglected in HCCI engines because the convective force from the gases to the cylinder walls is dominant in the heat transfer mechanism [70]. In the thermodynamics model, the convective heat transfer was predicted to match the experimental results because the model did not permit a full prediction of the in-cylinder gas motion [71]. The convective heat transfer rate can be described by Newton's law of cooling [72], as given by 


$$
\frac{d Q_{h}}{d t}=h_{c} A_{w}\left(T-T_{w}\right)
$$

where, $h_{c}$ is the heat transfer coefficient, $A_{w}$ is the cylinder wall area and $T_{w}$ is the wall temperature. The wall area is the sum of the cylinder wall, piston crown, and cylinder head areas. In a zero-dimensional simulation, the heat transfer coefficient has to be modeled, wherein the model attempts to reproduce the heat release rate obtained from the experiments. In this study, a modified Woschni heat transfer coefficient model was used, in which the model had been developed for HCCI engines; the measurements were taken in the piston crown and cylinder head areas [72]. The equation is given by

$$
h_{c}=194.7 L^{-0.2} P^{0.8} T^{-0.73}\left(v_{\text {tuned }}\right)^{0.8}
$$

where, the characteristic velocity $v_{\text {tuned }}$ is

$$
v_{\text {tuned }}=C_{1} \overline{S_{p}}+\frac{C_{2}}{6} \frac{V_{d} T_{r}}{P_{r} V_{r}}\left(P-P_{\text {mot }}\right)
$$

In equation (19) and (20), $L$ is the characteristic length scale, $C_{1}$ and $C_{2}$ are constants with values 2.28 and 0.00324 , respectively, $V_{d}$ is the displacement volume, subscript $r$ is the reference condition, and $P_{m o t}$ is the motoring pressure: a cylinder pressure without combustion. The effect of different heat transfer coefficient models had been discussed by Hairuddin, Wandel [1].

Table 1. Engine parameters used in the current study, ATDC is after top dead center, ABDC is after bottom dead center, BBDC is before bottom dead center [73].

\begin{tabular}{ll}
\hline Engine Parameters & \\
\hline Cylinder bore & $82.55 \mathrm{~mm}$ \\
Stroke & $114.3 \mathrm{~mm}$ \\
Connecting rod length & $254 \mathrm{~mm}$ \\
Compression ratio (CR) & 10 \\
Engine speed & $900 \mathrm{rpm}$ \\
Inlet valve open (IVO) & $10^{\circ} \mathrm{CA}$ ATDC \\
Inlet valve closed (IVC) & $36^{\circ} \mathrm{CA} \mathrm{ABDC}$ \\
Exhaust valve open (EVO) & $40^{\circ} \mathrm{CA}$ BBDC \\
Exhaust valve closed & $5^{\circ} \mathrm{CA}$ ATDC \\
\hline
\end{tabular}

\section{RESULTS AND DISCUSSION}

The model was validated against experimental results before proceeding with further analysis, where the experiment was run by using $n$-heptane as a fuel with port injection in a single-cylinder HCCI engine [73]. The model was also compared with their thermodynamics model. The engine parameters used in this study are shown in Table 1. The mixing effect must be taken into consideration because the fuel was port injected; thus, the effective intake temperature was set $20^{\circ} \mathrm{C}$ higher than the desired intake temperature [73]. Therefore, the intake temperature for the zero-dimensional model in this study was increased to $333 \mathrm{~K}$ for the intake temperature of $313 \mathrm{~K}$. The simulation result was compared with the experimental data and another single-zone model in Figure 
2. The validated result was completed using a modified Woschni heat transfer coefficient with an air-to-fuel ratio (AFR) of 50. The in-cylinder peak pressure was slightly higher than the experiment due to the limitation of the zero-dimensional single-zone model: it was assumed that the entire combustion chamber was homogeneous. Overall, the combustion phasing was in good agreement with the experimental data, demonstrating that the single-zone model was suitable for use in diesel HCCI engine simulations.

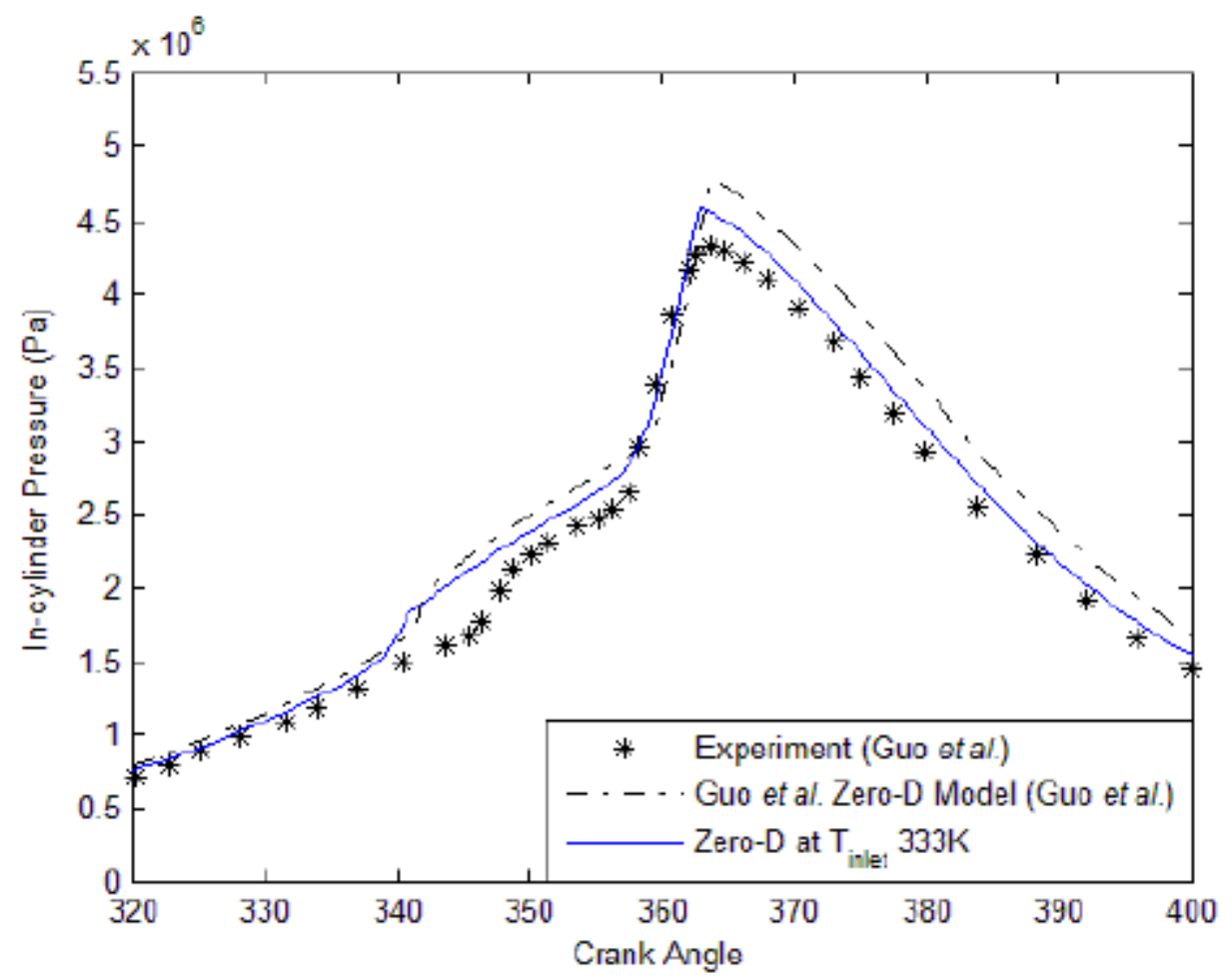

Figure 2. Comparison between single-zone zero-dimensional model with the experiment and another single-zone model using modified Woschni heat transfer coefficient model

[73]. $\mathrm{CR}=10.0, \mathrm{~N}=900 \mathrm{rpm}, \mathrm{T}_{\text {in }}=40^{\circ} \mathrm{C}, \mathrm{P}_{\text {in }}=95 \mathrm{kPa}, \mathrm{AFR}=50$

\section{Chemical Reactions}

The combustion event can be observed when there is a sharp increase in the temperature, as shown in Figure 3. This occurred when the piston approached the top dead center. Then, the ignition occurred when the temperature reached between 1000 and $1100 \mathrm{~K}$. The combustion in HCCI engines was fully controlled by chemical kinetics and Flowers, Aceves [74] have described the HCCI ignition by $\mathrm{H}_{2} \mathrm{O}_{2}$ decomposition. Figure 3 shows that radicals $\mathrm{H}_{2} \mathrm{O}_{2}, \mathrm{HO}_{2}$ and $\mathrm{OH}$ were selected because these were the most important in driving the ignition process. $\mathrm{H}_{2} \mathrm{O}_{2}$ and $\mathrm{HO}_{2}$ were related with LTR, wherein these radicals started to accumulate when the temperature was between 800 and $900 \mathrm{~K}$. OH had reached its first peak when LTR occurred and it started to accumulate again when approaching the HTR region. Once the in-cylinder temperature reached 1000-1100 K, $\mathrm{H}_{2} \mathrm{O}_{2}$ decomposed rapidly and formed a significant amount of $\mathrm{OH}$ radicals [60]. The fuel $\left(\mathrm{nC}_{7} \mathrm{H}_{16}\right)$ was consumed when $\mathrm{OH}$ was formed; at the same time, the amount of $\mathrm{H}_{2} \mathrm{O}_{2}$ reduced rapidly. The amount of fuel started to decrease at the LTR region by forming $\mathrm{H}_{2} \mathrm{O}_{2}$ and $\mathrm{HO}_{2}$. The fuel was completely being consumed when $\mathrm{OH}$ radicals reached their peak during the main combustion event: $\mathrm{H}_{2} \mathrm{O}_{2}$ had been fully decomposed. The time for $\mathrm{H}_{2} \mathrm{O}_{2}$ to completely decompose into $\mathrm{OH}$ radicals was very short, which was about $5^{\circ} \mathrm{CA}$. If the engine speed was increased, the chance for $\mathrm{H}_{2} \mathrm{O}_{2}$ to form enough amount of $\mathrm{OH}$ to 
consume the fuel was very minimal. This would create a combustion that was difficult to achieve when the engine speed was increased and HCCI was not achieveable in this condition. In general, the combustion event for a diesel HCCI engine can be seen in this model using the Cantera package and could be used in future studies.

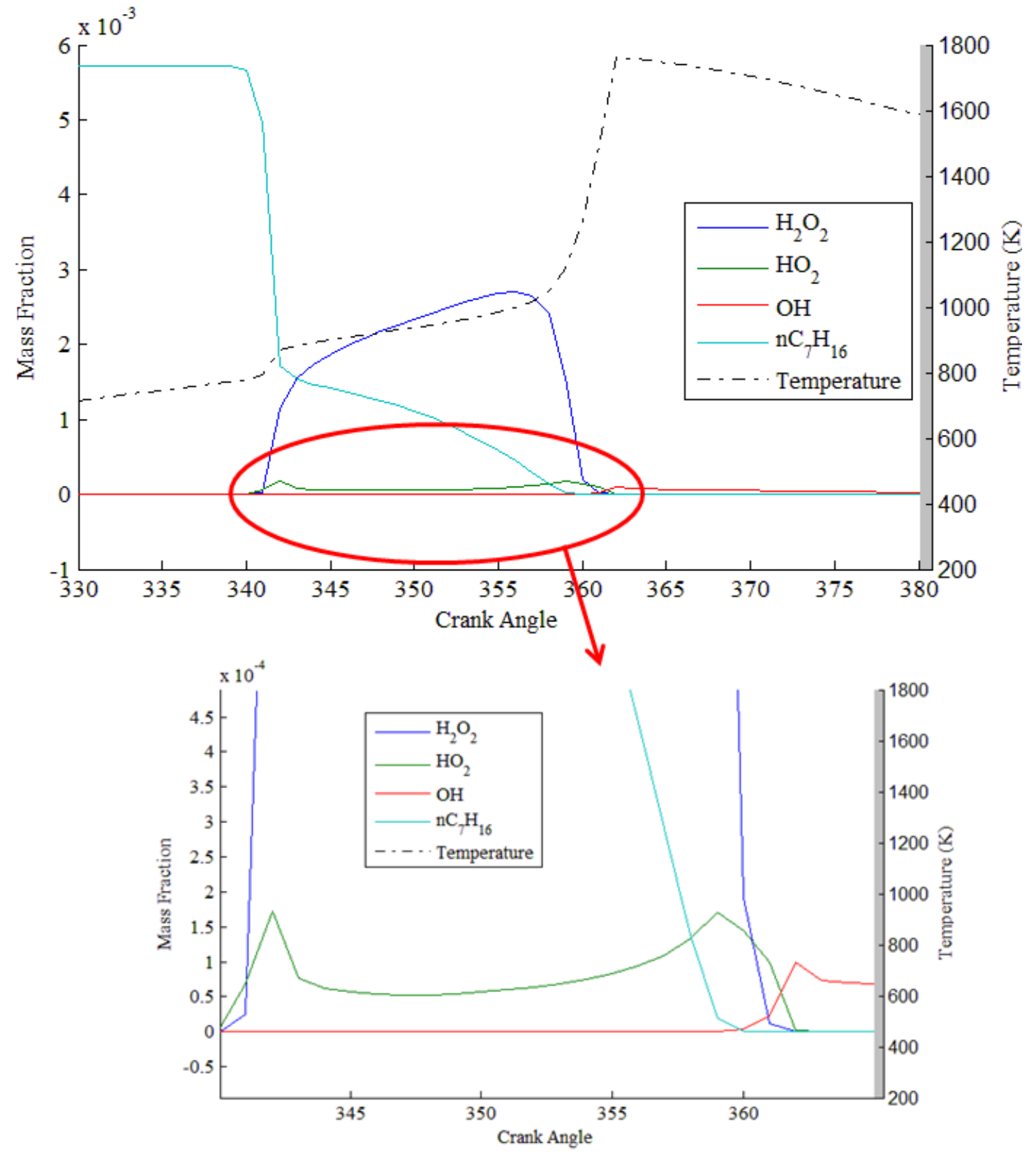

Figure 3. Species mass fraction of $\mathrm{nC}_{7} \mathrm{H}_{16}, \mathrm{H}_{2} \mathrm{O}_{2}, \mathrm{HO}_{2}$, and $\mathrm{OH}$ along with the temperature trend during combustion events. The figure is enlarged within the red circle to increase the image of the mass fraction trend of $\mathrm{HO}_{2}$ and $\mathrm{OH}$. Simulated at $\mathrm{CR}=10.0$, $\mathrm{N}=900 \mathrm{rpm}, \mathrm{T}_{\mathrm{in}}=40^{\circ} \mathrm{C}, \mathrm{P}_{\text {in }}=95 \mathrm{kPa}, \mathrm{AFR}=50$. 


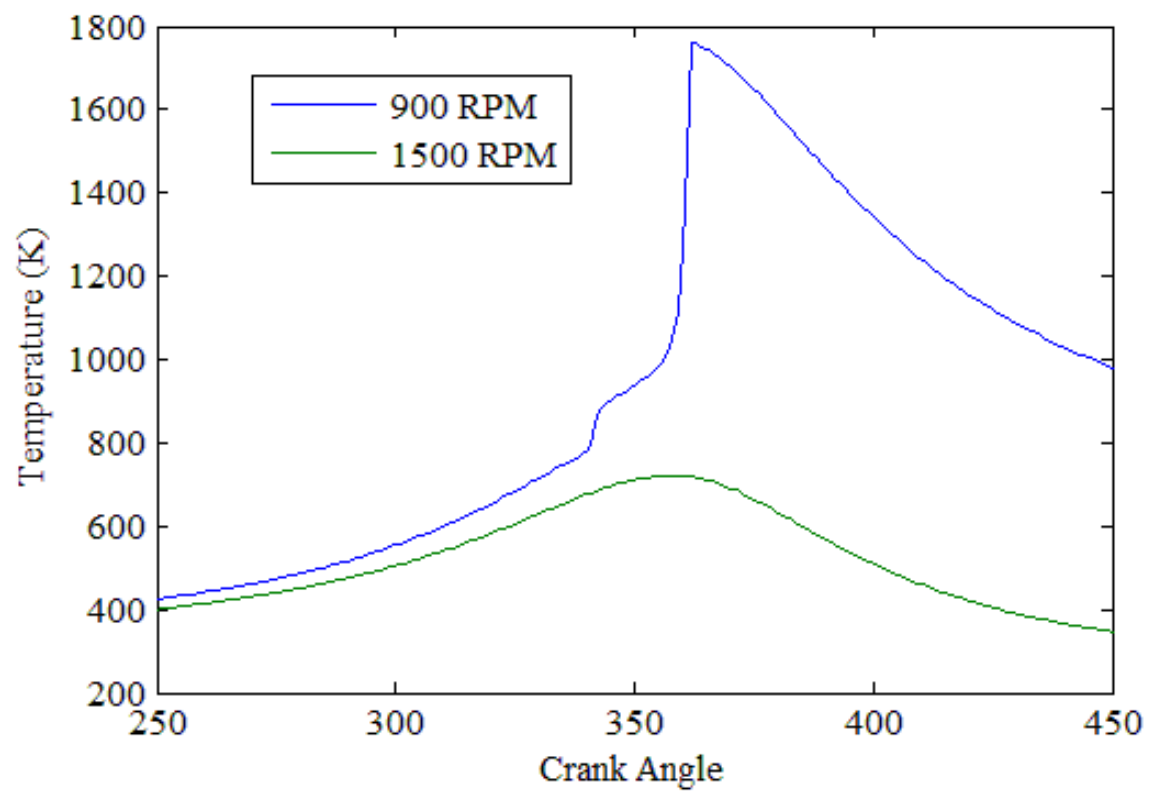

Figure 4. The difference in in-cylinder pressure when simulated at different engine speeds with the same operating condition: $\mathrm{CR}=10.0, \mathrm{~T}_{\mathrm{in}}=40^{\circ} \mathrm{C}, \mathrm{P}_{\text {in }}=95 \mathrm{kPa}, \mathrm{AFR}=50$.

\section{Effect of Varying Engine Speed}

The engine speed is one of the factors that influence the chemical reactions: higher engine speeds require fast combustion. When the engine was operated at the same condition, increasing the engine speed from 900 to $1500 \mathrm{rpm}$ will stop the HCCI combustion, as shown in Figure 4. The maximum in-cylinder temperature at $1500 \mathrm{rpm}$ was about $700 \mathrm{~K}$, which was not enough to initiate the accumulation of $\mathrm{H}_{2} \mathrm{O}_{2}$ and $\mathrm{HO}_{2}$. Figure 5 shows the mass fraction comparison of $\mathrm{H}_{2} \mathrm{O}_{2}, \mathrm{nC}_{7} \mathrm{H}_{16}$ and $\mathrm{OH}$ between the two different engine speeds: 900 and $1500 \mathrm{rpm}$. At $900 \mathrm{rpm}$, the fuel was entirely consumed when the $\mathrm{OH}$ was fully formed due to the decomposition of $\mathrm{H}_{2} \mathrm{O}_{2}$. The amount of fuel also started to reduce when the radical $\mathrm{H}_{2} \mathrm{O}_{2}$ began to accumulate. However, at a higher engine speed (1500 $\mathrm{rpm}$ ), there was no accumulation of $\mathrm{H}_{2} \mathrm{O}_{2}$. This was because there was not enough time for $\mathrm{H}_{2} \mathrm{O}_{2}$ and $\mathrm{HO}_{2}$ to start the reactions. The radical $\mathrm{HO}_{2}$ was not shown in the figure because the amount was very small. Thus, there was no reduction in fuel mass fraction, which indicated there was no combustion at $1500 \mathrm{rpm}$, given the same operating condition. Therefore, increasing the engine speed without changing any of the factors resulted in a no combustion event occurring, in addition to the difficulty in controlling the ignition timing. Increasing the engine speed was necessary when more loads were required from the engine. The fuel will become more susceptible to combustion by increasing its chemical energy. This was achieved by changing a few other parameters, such as the intake temperature or AFR to the mixture; these parameters can be used to control the ignition timing of a diesel HCCI engine.

\section{Effect of Intake Temperature}

Intake air temperature is an important factor for controlling the auto-ignition timing of HCCI engines. Different fuels have different auto-ignition points and some of them require pre-heating to achieve good combustion. If methane or natural gas is used as a fuel, the intake air temperature has to be set to at least $400 \mathrm{~K}$ to achieve an appropriate ignition [75]. Therefore, the intake temperature will affect the auto-ignition point for other 
fuels as well and increasing the intake temperature will reduce the ignition delay. Thus, the auto-ignition timing can be controlled.

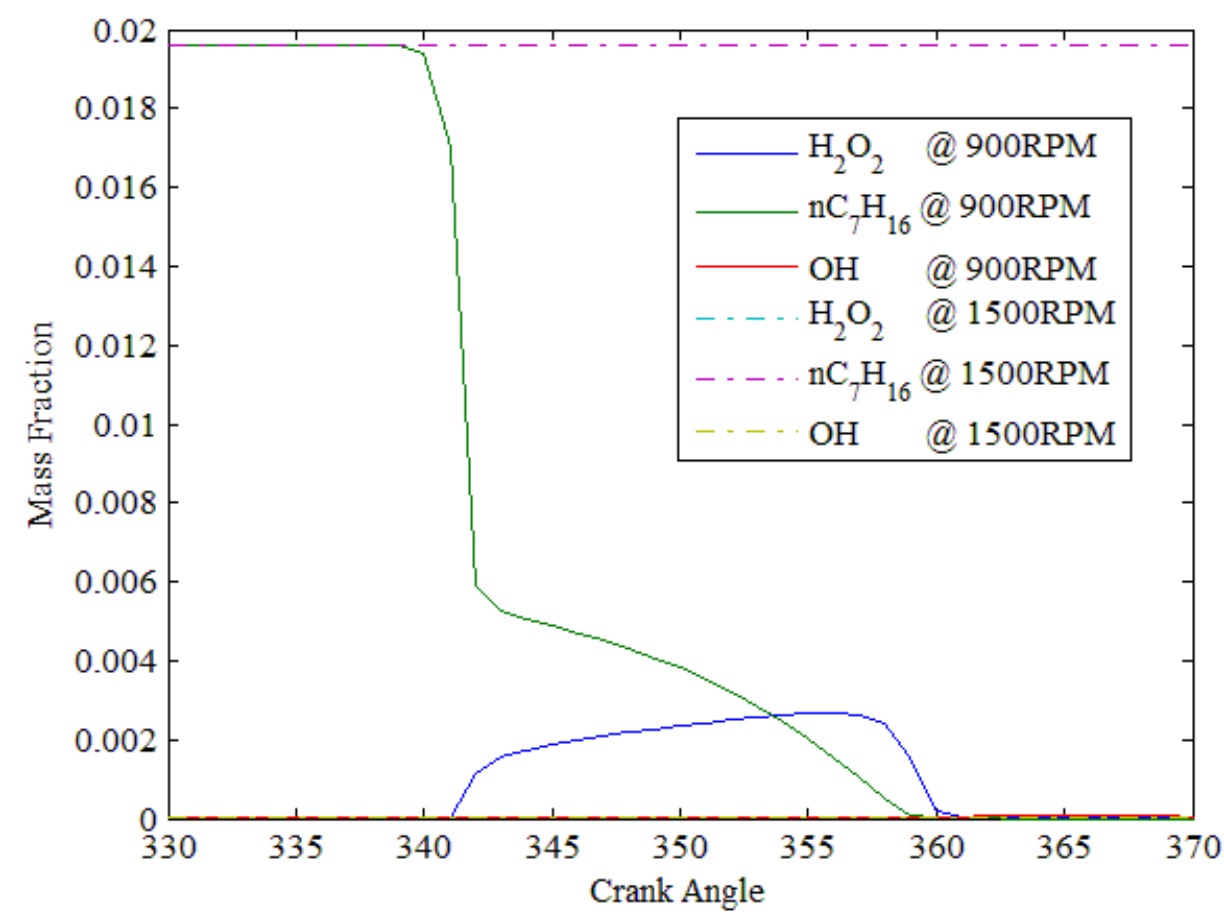

Figure 5. Species mass fraction comparison of $\mathrm{H}_{2} \mathrm{O}_{2}, \mathrm{nC}_{7} \mathrm{H}_{16}$ and $\mathrm{OH}$ at two different engine speeds: 900 and $1500 \mathrm{rpm}$. Simulated at $\mathrm{CR}=10.0, \mathrm{~T}_{\mathrm{in}}=40^{\circ} \mathrm{C}, \mathrm{P}_{\mathrm{in}}=95 \mathrm{kPa}$,

$\mathrm{AFR}=50$.
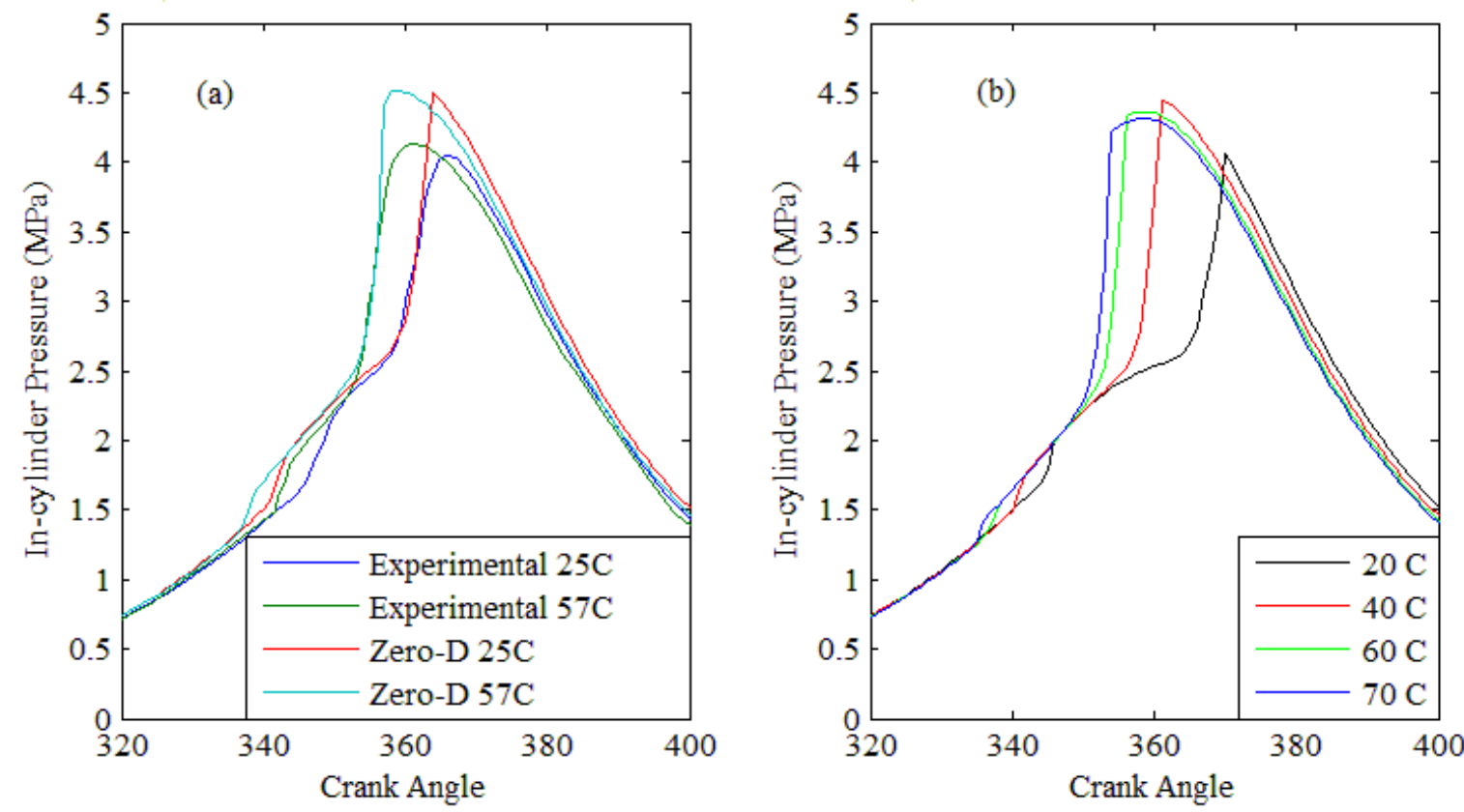

Figure 6. Effect of intake temperature on the in-cylinder pressure: $C R=10.0, N=900$ $\mathrm{rpm}, \mathrm{P}_{\text {in }}=95 \mathrm{kPa}, \mathrm{AFR}=50$ (a) Validated varying intake temperature against experimental from Guo et al. [59]; (b) Predicted in-cylinder pressure trend. 
Figure 6 shows that the auto-ignition timing can be advanced once the intake temperature is increased. Results from the current simulation were compared with the experimental results [59] in Figure 6(a) to validate the model over different operating temperatures; the results were similar to those in Figure 2. An increase in air intake temperature will not affect the in-cylinder peak pressure significantly. Note the trend as the intake temperature increases: the predicted in-cylinder peak pressure starts to decrease, even though the autoignition is advanced, as shown in Figure 6(b). This trend was also observed in the experiment [73]. This is a good option for control because of the low increase in incylinder peak pressure.

\section{Effect of AFR}

The AFR is a measure of how much air and fuel is being consumed in the combustion chamber; diesel HCCI engines operated with lean mixtures (AFR $>\mathrm{AFR}_{\text {stoich }}$ ) with $\mathrm{AFR}_{\text {stoich }}$ of about 14.5. Figure 7(a) shows the validated result of different AFRs compared with the experiment, again showing a good agreement. Meanwhile, Figure 7(b) shows the predicted result of reducing the AFR: an increase in the in-cylinder peak pressure and advancement of the auto-ignition timing. The in-cylinder peak pressure trend kept increasing with the reducing AFR, which will create knocking. In addition, the start of LTR was retarded with a reduction of AFR. However, if the mixture became too rich, the auto-ignition was advanced significantly, which will lead to knocking: an undesired combustion phenomenon. Therefore, careful tuning was needed to adapt to dynamic engine loads.
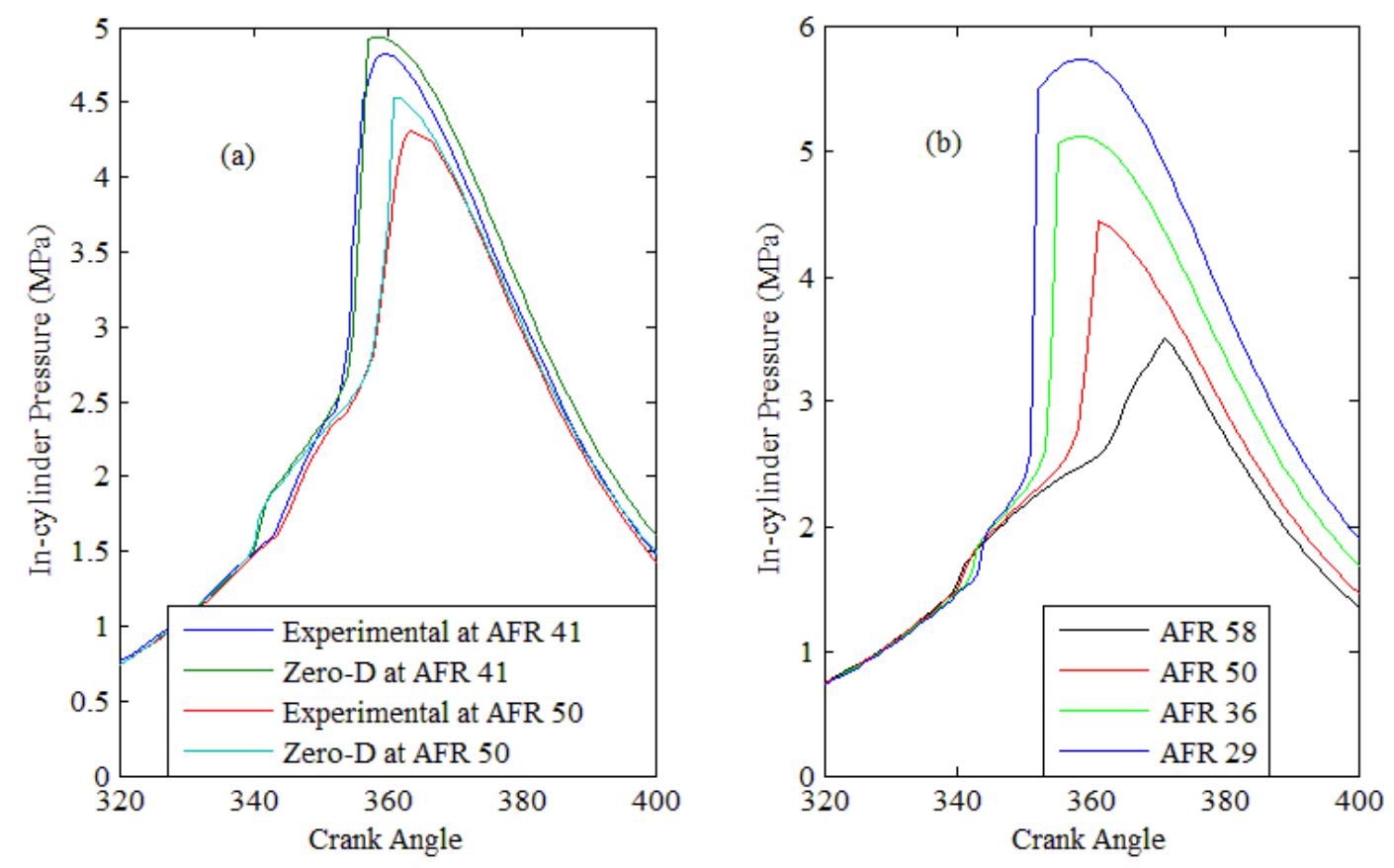

Figure 7. Effect of AFR on the in-cylinder pressure: $\mathrm{CR}=10.0, \mathrm{~N}=900 \mathrm{rpm}, \mathrm{T}_{\mathrm{in}}=40^{\circ} \mathrm{C}$, $\mathrm{P}_{\text {in }}=95 \mathrm{kPa}$ (a) Validated varying AFR against the experiment from Guo et al. [59];

(b) Predicted in-cylinder pressure. 


\section{CONCLUSIONS}

This paper had discussed a zero-dimensional model for a diesel HCCI engine using an open source chemical kinetics package, Cantera. The model had been validated and it was in agreement with the experimental data. In general, the following applied:

1. A zero-dimensional model is a useful and faster tool to predict the combustion phasing. A combination with chemical kinetics model gives relatively accurate results, provided that the conditions have been set correctly.

2. An open source chemical kinetics package, Cantera, is beneficial for researchers to simulate chemical reactions at no cost.

3. Three different heat transfer coefficient models had been investigated: the Woschni, modified Woschni, and Hohenberg models. The models are very sensitive to the temperature exponent under normal operating conditions. It was found that a modified Woschni correlation produced a more accurate result compared with the other two models and can be used for further analysis of a diesel HCCI engine.

4. Higher engine speed leads to a shorter decomposition time of $\mathrm{H}_{2} \mathrm{O}_{2}$ radicals. Thus, increasing the engine speed will make the HCCI combustion difficult to achieve when given the same operating conditions.

5. Intake temperature and AFR can be used as an ignition control for HCCI combustion. It was found that the combustion phasing was advanced by increasing all of the parameters (intake temperature, equivalence ratio, and energy ratio); therefore, the auto-ignition can be controlled.

\section{ACKNOWLEDGEMENTS}

The authors would like to be obliged to Universiti Putra Malaysia for providing research facilities and University of Southern Queensland for the research support. The study is also supported financially by IPM Putra Grant under project no. GP-IPM 9483100.

\section{REFERENCES}

[1] Hairuddin AA, Wandel AP, Yusaf T. Effect of different heat transfer models on a diesel homogeneous charge compression ignition engine. International Journal of Automotive and Mechanical Engineering. 2013;8:1292.

[2] Hasan M, Rahman M, Kadirgama K. A review on homogeneous charge compression ignition engine performance using biodiesel-diesel blend as a fuel. International Journal of Automotive and Mechanical Engineering. 2015;11:2199.

[3] Janhunen TT. HCCI-combustion in the Z engine. SAE Technical Paper; 2012.

[4] Naiki T, Iida N, Lhomme C. An investigation of the effects of fuel inhomogeneity on the pressure rise rate in $\mathrm{HCCI}$ engine using chemiluminescence imaging. SAE Technical Paper; 2010.

[5] Noor M, Wandel AP, Yusaf T. Analysis of recirculation zone and ignition position of non-premixed bluff-body for biogas mild combustion. International Journal of Automotive and Mechanical Engineering. 2013;8:1176.

[6] Yun H, Wermuth N, Najt P. High load HCCI operation using different valving strategies in a naturally-aspirated gasoline HCCI engine. SAE International Journal of Engines. 2011;4:1190-201. 
[7] Wesselink L, Buijsman E, Annema J. The impact of Euro 5: facts and figures. The Netherlands. 2006.

[8] EPA. Control of air pollution from new motor vehicles: Tier 2 motor vehicle emissions standards and gasoline sulfur control requirements. Air and Radiation. United States: U.S. Environmental Protection Agency; 2000.

[9] Popp D. International innovation and diffusion of air pollution control technologies: the effects of NOX and SO 2 regulation in the US, Japan, and Germany. Journal of Environmental Economics and Management. 2006;51:4671.

[10] Onishi S, Jo SH, Shoda K, Do Jo P, Kato S. Active thermo-atmosphere combustion (ATAC)-a new combustion process for internal combustion engines. SAE Technical paper; 1979.

[11] Raitanapaibule K, Aung K. Performance predictions of a hydrogen-enhanced natural gas HCCI engine. ASME 2005 International Mechanical Engineering Congress and Exposition: American Society of Mechanical Engineers; 2005. p. 289-94.

[12] Sathiyamoorthi R, Sankaranarayanan G. Fuel Injection Timings of a Direct Injection Diesel Engine Running on Neat Lemongrass Oil-Diesel Blends. International Journal of Automotive and Mechanical Engineering. 2015;11:234863.

[13] Babu AR, Amba Prasad Rao G, Hari Prasad T. Direct injection of water mist in an intake manifold spark ignition engine. International Journal of Automotive and Mechanical Engineering. 2015;12:2809-19.

[14] Mohanamurugan S, Sendilvelan S. Emission and Combustion Characteristics of Different Fuel In A HCCI Engine. International Journal of Automotive and Mechanical Engineering. 2011;3:279-92.

[15] Kong S-C, Reitz RD. Use of detailed chemical kinetics to study HCCI engine combustion with consideration of turbulent mixing effects. Journal of Engineering for Gas Turbines and Power. 2002;124:702-7.

[16] Ramasamy D, Kadirgama K, Rahman MM, Zainal ZA. Analysis of compressed natural gas burn rate and flame propagation on a sub-compact vehicle engine. International Journal of Automotive and Mechanical Engineering. 2015;11:240516.

[17] Ramasamy D, Zainal Z, Kadirgama K, Briggs HW-G. Effect of dissimilar valve lift on a bi-fuel CNG engine operation. Energy. 2016;112:509-19.

[18] Hairuddin AA, Wandel AP, Yusaf T. An introduction to a homogeneous charge compression ignition engine. Journal of Mechanical Engineering and Sciences. 2014; 7:1042-52.

[19] Najt PM, Foster DE. Compression-ignited homogeneous charge combustion. SAE Technical paper; 1983.

[20] Jun D, Ishii K, Iida N. Autoignition and Combustion of Natural Gas in a 4 Stroke HCCI Engine. JSME International Journal Series B Fluids and Thermal Engineering. 2003;46:60-7.

[21] Kong S-C, Reitz RD. Numerical study of premixed HCCI engine combustion and its sensitivity to computational mesh and model uncertainties. Combustion Theory and Modelling. 2003;7:417-33.

[22] Nathan SS, Mallikarjuna J, Ramesh A. An experimental study of the biogas-diesel HCCI mode of engine operation. Energy Conversion and Management. 2010;51:1347-53. 
[23] Soylu S. Prediction of knock limited operating conditions of a natural gas engine. Energy Conversion and Management. 2005;46:121-38.

[24] Killingsworth NJ, Aceves SM, Flowers DL, Krstic M. A simple HCCI engine model for control. 2006 IEEE Conference on Computer Aided Control System Design, 2006 IEEE International Conference on Control Applications, 2006 IEEE International Symposium on Intelligent Control: IEEE; 2006. p. 2424-9.

[25] Mack JH, Aceves SM, Dibble RW. Demonstrating direct use of wet ethanol in a homogeneous charge compression ignition (HCCI) engine. Energy. 2009;34:7827.

[26] Aceves SM, Flowers DL, Martinez-Frias J, Espinosa-Loza F, Christensen M, Johansson B, et al. Analysis of the effect of geometry generated turbulence on HCCI combustion by multi-zone modeling. SAE Technical Paper; 2005.

[27] Christensen M, Johansson B, Einewall P. Homogeneous charge compression ignition (HCCI) using isooctane, ethanol and natural gas-a comparison with spark ignition operation. SAE Technical Paper; 1997.

[28] Epping K, Aceves S, Bechtold R, Dec JE. The potential of HCCI combustion for high efficiency and low emissions. SAE Technical Paper; 2002.

[29] Hiltner J, Fiveland S, Agama R, Willi M. System efficiency issues for natural gas fueled HCCI engines in heavy-duty stationary applications. SAE Technical Paper; 2002.

[30] Kawano D, Suzuki H, Ishii H, Goto Y, Odaka M, Murata Y, et al. Ignition and combustion control of diesel HCCI. SAE Technical Paper; 2005.

[31] Shukri MR, Rahman MM, Ramasamy D, Kadirgama K. Artificial Neural Network Optimization Modeling on Engine Performance of Diesel Engine Using Biodiesel Fuel. International Journal of Automotive and Mechanical Engineering. 2015;11:2332-47.

[32] Ghafoori M, Ghobadian B, Najafi G, Layeghi M, Rashidi A, Mamat R. Effect of nano-particles on the performance and emission of a diesel engine using biodieseldiesel blend. International Journal of Automotive and Mechanical Engineering. 2015;12:3097-108.

[33] Azad AK, Rasul MG, Giannangelo B, Islam R. Comparative study of diesel engine performance and emission with soybean and waste oil biodiesel fuels. International Journal of Automotive and Mechanical Engineering. 2015;12:286681.

[34] Akasyah MK, Mamat R, Abdullah A, Aziz A, Yassin HM. Effect of ambient temperature on diesel-engine combustion characteristics operating with alcohol fuel. International Journal of Automotive and Mechanical Engineering. 2015;11:2373-82.

[35] Johansson B. Homogeneous charge compression ignition: the future of IC engines? International journal of vehicle design. 2007;44:1-19.

[36] Serinyel Z, Le Moyne L, Guibert P. Homogeneous charge compression ignition as an alternative combustion mode for the future of internal combustion engines. International journal of vehicle design. 2007;44:20-40.

[37] Firmansyah, Aziz ARA. Investigation of auto-ignition of octane-cng mixture in HCCI engine. International Journal of Automotive and Mechanical Engineering. 2015;11:2235-42.

[38] Lin L, Cunshan Z, Vittayapadung S, Xiangqian S, Mingdong D. Opportunities and challenges for biodiesel fuel. Applied Energy. 2011;88:1020-31. 
[39] Li Y-G, Xu L, Huang Y-M, Wang F, Guo C, Liu C-Z. Microalgal biodiesel in China: opportunities and challenges. Applied Energy. 2011;88:3432-7.

[40] Lai JY, Lin KC, Violi A. Biodiesel combustion: advances in chemical kinetic modeling. Progress in Energy and Combustion Science. 2011;37:1-14.

[41] Amaro HM, Guedes AC, Malcata FX. Advances and perspectives in using microalgae to produce biodiesel. Applied Energy. 2011;88:3402-10.

[42] $\mathrm{Ng} \mathrm{J}-\mathrm{H}, \mathrm{Ng} \mathrm{HK}$, Gan S. Advances in biodiesel fuel for application in compression ignition engines. Clean technologies and environmental policy. 2010;12:459-93.

[43] Demirbas A. Political, economic and environmental impacts of biofuels: a review. Applied energy. 2009;86:S108-S17.

[44] Shahid EM, Jamal Y. A review of biodiesel as vehicular fuel. Renewable and Sustainable Energy Reviews. 2008;12:2484-94.

[45] Pasternak M, Mauss F, Sens M, Riess M, Benz A, Stapf KG. Gasoline engine simulations using zero-dimensional spark ignition stochastic reactor model and three-dimensional computational fluid dynamics engine model. International Journal of Engine Research. 2016;17:76-85.

[46] Kumar P, Rehman A. Bio-diesel in homogeneous charge compression ignition (HCCI) combustion. Renewable and Sustainable Energy Reviews. 2016;56:53650 .

[47] Turkcan A, Ozsezen AN, Canakci M, Coskun G, Soyhan HS, Demir U. An Experimental and Modeling Study to Investigate Effects of Two-Stage Direct Injection Variations on HCCI Combustion. Combustion Science and Technology. 2015;187:642-58.

[48] Cinar C, Uyumaz A, Solmaz H, Sahin F, Polat S, Yilmaz E. Effects of intake air temperature on combustion, performance and emission characteristics of a HCCI engine fueled with the blends of $20 \%$ n-heptane and $80 \%$ isooctane fuels. Fuel Processing Technology. 2015;130:275-81.

[49] Visakhamoorthy S, Tzanetakis T, Haggith D, Sobiesiak A, Wen JZ. Numerical study of a homogeneous charge compression ignition (HCCI) engine fueled with biogas. Applied Energy. 2012;92:437-46.

[50] Wang Z, Shuai S-J, Wang J-X, Zhang F. Numerical simulation of gasoline stratified charge compression ignition using 3D-CFD coupled with detailed chemistry. Combustion Science and Technology. 2008;180:1295-316.

[51] Zheng QP, Zhang HM. A computational study of combustion in compression ignition natural gas engine with separated chamber. Fuel. 2005;84:1515-23.

[52] Agarwal A, Assanis DN. Multi-dimensional modeling of natural gas ignition under compression ignition conditions using detailed chemistry. SAE Technical Paper; 1998.

[53] Agarwal A, Assanis DN. Multi-dimensional modeling of ignition, combustion and nitric oxide formation in direct injection natural gas engines. SAE Technical Paper; 2000.

[54] Babajimopoulos A, Lavoie GA, Assanis DN. Modeling HCCI combustion with high levels of residual gas fraction-A comparison of two VVA strategies. SAE Technical paper; 2003.

[55] Chen Z, Konno M, Goto S. Study on homogenous premixed charge CI engine fueled with LPG. JSAE review. 2001;22:265-70.

[56] McTaggart-Cowan G, Wu N, Jin B, Rogak S, Davy MH, Bushe W. Effects of fuel composition on high-pressure non-premixed natural gas combustion. Combustion Science and Technology. 2009;181:397-416. 
[57] Devarajan Ramasamy KK, Z.A Zainal, R.A.Bakar, Yusoff Ali. Experimental And Simulation Analysis Of Compressed Natural Gas Burn Rate And Flame Propagation On A Sub-Compact Vehicle Engine. International Conference on Automotive Innovation and Green Energy Vehicle (AiGEV 2014). Swiss Garden Resort \& Spa: UMP; 2014.

[58] Ramasamy D, Aik Soon K, Walker-Gitano Briggs H, Zainal ZA. Variation of airflow pattern through dissimilar valve lift in a spark ignition engine. Journal of the Chinese Institute of Engineers, Transactions of the Chinese Institute of Engineers,Series A/Chung-kuo Kung Ch'eng Hsuch K'an. 2013;36:1083-96.

[59] Ramasamy D, Yuan GC, Bakar RA, Zainal ZA. Validation of road load characteristic of a sub-compact vehicle by engine operation. International Journal of Automotive and Mechanical Engineering. 2014;9:1820-31.

[60] Aceves SM, Flowers DL, Westbrook CK, Smith JR, Pitz W, Dibble R, et al. A multi-zone model for prediction of HCCI combustion and emissions. SAE Technical paper; 2000.

[61] Goodwin D. An open-source, extensible software suite for CVD process simulation. Chemical Vapor Deposition XVI and EUROCVD. 2003;14:2003-08.

[62] Wang Z, Shuai S-J, Wang J-X, Tian G-H. A computational study of direct injection gasoline HCCI engine with secondary injection. Fuel. 2006;85:1831-41.

[63] Fengjun G, Yingnan G, Fafa L, Hua L, Honggang J, Manzhi T. Control of HCCI engine fueled with gasoline with electro-hydraulic variable valve system. Informatics in Control, Automation and Robotics (CAR), 2010 2nd International Asia Conference on: IEEE; 2010. p. 250-3.

[64] Kong S-C, Reitz RD. Application of detailed chemistry and CFD for predicting direct injection HCCI engine combustion and emissions. Proceedings of the Combustion Institute. 2002;29:663-9.

[65] Assanis DN, Heywood JB. Development and use of a computer simulation of the turbocompounded diesel system for engine performance and component heat transfer studies. SAE Technical Paper; 1986.

[66] Assanis D, Polishak M. Valve event optimization in a spark-ignition engine. Journal of engineering for gas turbines and power. 1990;112:341-7.

[67] Heywood JB. Internal combustion engine fundamentals: Mcgraw-hill New York; 1988.

[68] Stiesch G. Modeling engine spray and combustion processes: Springer Science \& Business Media; 2013.

[69] Seiser R, Pitsch H, Seshadri K, Pitz W, Gurran H. Extinction and autoignition of n-heptane in counterflow configuration. Proceedings of the Combustion Institute. 2000;28:2029-37.

[70] Soyhan H, Yasar H, Walmsley H, Head B, Kalghatgi G, Sorusbay C. Evaluation of heat transfer correlations for HCCI engine modeling. Applied Thermal Engineering. 2009;29:541-9.

[71] Stone R. Introduction to internal combustion engines. 1999.

[72] Chang J, Güralp O, Filipi Z, Assanis DN, Kuo T-W, Najt P, et al. New heat transfer correlation for an HCCI engine derived from measurements of instantaneous surface heat flux. SAE Technical paper; 2004.

[73] Guo H, Neill WS, Chippior W, Li H, Taylor JD. An experimental and modeling study of HCCI combustion using n-heptane. Journal of Engineering for Gas Turbines and Power. 2010;132:022801. 
[74] Flowers D, Aceves S, Westbrook C, Smith J, Dibble R. Detailed chemical kinetic simulation of natural gas HCCI combustion: gas composition effects and investigation of control strategies. Journal of engineering for gas turbines and power. 2001;123:433-9.

[75] Morsy MH. Ignition control of methane fueled homogeneous charge compression ignition engines using additives. Fuel. 2007;86:533-40.

\section{APPENDICES}

The derivation of temperature changes in a zero-dimensional single-zone model from the first law of thermodynamics equations. The first law of thermodynamics equation is

$$
U=-W+Q_{h}+\sum_{j} m_{j} h_{j}
$$

where $j$ is the number of flows entering or leaving the system. Differentiating equation (1) with time gives

$$
\frac{d(m u)}{d t}=-P \frac{d V}{d t}+\frac{d Q_{h}}{d t}+\sum_{j} \dot{m}_{j} h_{j}
$$

Knowing that the enthalpy for a homogenous system is defined as

$$
h=u+P V
$$

Substituting equation (3) to (2) yields

$$
\frac{d(m h)}{d t}-\frac{d(P V)}{d t}=\frac{d Q_{h}}{d t}-P \frac{d V}{d t}+\sum_{j} h_{j} \frac{d m_{j}}{d t}
$$

Manipulating of equation (4) becomes

$$
\begin{gathered}
m \frac{d h}{d t}+\mathrm{h} \frac{d m}{d t}-\mathrm{P} \frac{d V}{d t}-\mathrm{V} \frac{d P}{d t}=\frac{d Q_{h}}{d t}-P \frac{d V}{d t}+\sum_{j} h_{j} \frac{d m_{j}}{d t} \\
m \frac{d h}{d t}=\frac{d Q_{h}}{d t}+V \frac{d P}{d t}-h \frac{d m}{d t}+\sum_{j} h_{j} \frac{d m_{j}}{d t}
\end{gathered}
$$

In equation (6), an expression of $\frac{d h}{d t}$ in terms of changes in temperature needs to be developed. For a multi-component mixture of ideal gas and single phase,

$$
h=\sum_{i} Y_{i} h_{i} \quad \text { and } \quad h=h\left(T, P, Y_{i}\right)
$$

where, $i$ is the component species in the mixture. Partial differentials with respect to temperature, pressure and composition are 


$$
\frac{d h}{d t}=\left.\frac{\partial h}{\partial T}\right|_{P, Y_{i}} \frac{d T}{d t}+\left.\frac{\partial h}{\partial P}\right|_{T, Y_{i}} \frac{d P}{d t}+\left.\sum_{i} \frac{\partial h}{\partial Y_{i}}\right|_{P, T, Y_{i \neq j}} \frac{d Y_{i}}{d t}
$$

The partial change of enthalpy with respect to pressure at constant temperature and composition is zero, hence equation (8) becomes

$$
\frac{d h}{d t}=C_{p} \frac{d T}{d t}+\sum_{i} h_{i} \frac{d Y_{i}}{d t}
$$

The pressure gradient in equation (6) can be obtained by manipulating the equation of state for an ideal gas

$$
\begin{gathered}
P V=m R T \\
P \frac{d V}{d t}+V \frac{d P}{d t}=m R \frac{d T}{d t}+T \frac{d(m R)}{d t} \\
P \frac{d V}{d t}+V \frac{d P}{d t}=m R \frac{d T}{d t}+m T \frac{d R}{d t}+R T \frac{d m}{d t} \\
m T \frac{d R}{d t}=P \frac{d V}{d t}+V \frac{d P}{d t}-m R \frac{d T}{d t}-R T \frac{d m}{d t}
\end{gathered}
$$

Dividing both sides of equation (10) with $P V$ gives

$$
\frac{P V}{R} \frac{d R}{d t}=\frac{m R T}{V} \frac{d V}{d t}+\frac{m R T}{P} \frac{d P}{d t}-\frac{P V}{T} \frac{d T}{d t}-\frac{P V}{m} \frac{d m}{d t}
$$

Rearranging equation (11) gives

$$
\begin{gathered}
\frac{\dot{R}}{R}=\frac{m R T}{P V^{2}} \frac{d V}{d t}+\frac{m R T}{P^{2} V} \frac{d P}{d t}-\frac{\dot{T}}{T}-\frac{\dot{m}}{m} \\
\frac{\dot{R}}{R}=\frac{m R T}{m R T V} \frac{d V}{d t}+\frac{m R T}{m R T P} \frac{d P}{d t}-\frac{\dot{T}}{T}-\frac{\dot{m}}{m} \\
\frac{\dot{R}}{R}=\frac{\dot{V}}{V}+\frac{\dot{P}}{P}-\frac{\dot{T}}{T}-\frac{\dot{m}}{m}
\end{gathered}
$$

Knowing that

$$
\dot{R}=\sum_{i} R_{i} \dot{Y}_{i}
$$

Substituting equation (13) to (12), and rearranging gives

$$
\dot{P}=P\left[\frac{\sum_{i} R_{i} \dot{Y}_{i}}{R}+\frac{\dot{m}}{m}+\frac{\dot{T}}{T}-\frac{\dot{V}}{V}\right]
$$

Hence, substituting equation (14) to (6) and rearranging

$$
m \dot{h}=\sum_{j} \dot{m}_{j} h_{j}+\dot{Q}_{h}+P V\left[\frac{\sum_{i} R_{i} \dot{Y}_{i}}{R}+\frac{\dot{m}}{m}+\frac{\dot{T}}{T}-\frac{\dot{V}}{V}\right]-\dot{m} h
$$




$$
\begin{gathered}
m\left(C_{p} \dot{T}+\sum_{i} h_{i} \dot{Y}_{i}\right)=\sum_{j} \dot{m}_{j} h_{j}+\dot{Q}_{h}+P V\left[\frac{\sum_{i} R_{i} \dot{Y}_{i}}{R}+\frac{\dot{m}}{m}+\frac{\dot{T}}{T}-\frac{\dot{V}}{V}\right]-\dot{m} h \\
m C_{p} \dot{T}-P V \frac{\dot{T}}{T}=\sum_{j} \dot{m}_{j} h_{j}+\dot{Q}_{h}+\frac{P V}{R} \sum_{i} R_{i} \dot{Y}_{i}+\frac{P V}{m} \dot{m}-P \dot{V}-\dot{m} h \\
-m \sum_{i} h_{i} \dot{Y}_{i} \\
\dot{T}\left(m C_{p}-\frac{P V}{T}\right)=\sum_{j} \dot{m}_{j} h_{j}+\dot{Q}_{h}+\frac{P V}{R} \sum_{i} R_{i} \dot{Y}_{i}+\frac{P V}{m} \dot{m}-P \dot{V}-\dot{m} h \\
\quad-m \sum_{i} h_{i} \dot{Y}_{i} \\
\dot{T}\left(C_{p}-\frac{P V}{m T}\right)=\left(\frac{P v}{R} \sum_{i} R_{i}-\sum_{i} h_{i}\right) \dot{Y}_{i}+\sum_{j} \frac{\dot{m}_{j} h_{j}}{m}+\frac{\dot{Q}_{h}}{m}+P v \frac{\dot{m}}{m}-\frac{\dot{m}}{m} h-\frac{P \dot{V}}{m}
\end{gathered}
$$

The final equation is

$$
\dot{\mathrm{T}}=\frac{1}{A}\left[\left(\frac{P v \sum_{i} R_{i}}{R}-\sum_{i} h_{i}\right) \dot{Y}_{i}-\frac{\dot{m}}{m} B+\frac{1}{m}\left(\frac{d Q_{h}}{d t}-P \frac{d V}{d t}+\sum_{j} \dot{m}_{j} h_{j}\right)\right]
$$

where,

$$
\begin{gathered}
\mathrm{A}=\bar{C}_{p}-\frac{P v}{T} \\
B=h-P v
\end{gathered}
$$

